\title{
Technology as a driver of skills obsolescence and skills mismatch: Implications for the labour market, society and the economy
}

\author{
GRACIA SANTOSO
}

\section{Abstract}

The aim of this paper is to synthesise and build on the discourse of technological implications for the workforce in a post-information age. It has found that throughout history, the advance of technology is correlated with social issues, particularly issues of rising unemployment as a result of skills obsolescence and mismatch. However, as long as appropriate measures to adjust to technological changes are taken, unemployment will only remain as a temporary phase. The pursuit of lifelong learning and adoption of strategic human resource management is found to be an effective solution in bridging the gap and slowing down the rate of skills mismatch. Individuals can also pursue the increasing job opportunities emerging within knowledge-intensive and technology sectors. Furthermore, talent brokers have a growing role as an intermediary to the supply and demand of skills.

\section{Introduction}

Shaped by the ever-changing needs of society, technology has and continues to be a powerful driver of human development. The relationship between technology and society can be best described as a synergistic cycle of co-dependence, co-influence, and co-production (Puricelli 2011), in which the same technology borne from culture can in turn shape that very same culture. Evolving from simple survival tools of prehistoric times to the recent developments of modern technology, technology has grown to significantly affect the environment, society, and the entirety of the economy, including the labour market. In the late eighteenth century, mechanisation of the textile industry triggered the first industrial revolution, causing a shift of the workforce away from agriculture and towards manufacturing. In Britain alone, between the years 1500 and 1800 the percentage of the workforce dedicated to agriculture decreased from 75 per cent to 
less than 40 per cent (The Economist 2014). During the second industrial revolution in the early twentieth century, characterised by technological developments such as factory electrification, development of railroads, and the increasing use of machinery in manufacturing (The Economist 2012), jobs shifted yet again as society began to master the art of mass production, this time away from manufacturing and towards service provision (Blinder 2006; Stewart, De \& Cole 2015).

Thanks to the two industrial revolutions, society was able to transform into the wealthier and more urbanised world of today. However, while the continual pursuit of knowledge and technological developments allow society to accelerate social progress, it should be recognised that it has simultaneously contributed to economic inequality as a result of 'skill-biased technological changes' (Goldin \& Katz 2008). Skill-biased technological changes can be defined as the increase in the relative demand for high-skilled workers over low-skilled workers as a result of the introduction of a radically different and complex technology in the workplace. Such technological changes are classified as competence-destroying as they create major alterations in the distribution of power and control in a firm (Bhaskar, Bhal \& Ratnam 2003). Consequently, such skill differentiation enables firms to monopolise wages in the labour market (Thisse \& Zenou 2000; Vieira 2005; Greenspan 1996), which results in greater unemployment at the lower end of the wage distribution (Manacorda \& Petrongolo 1999). The rationale behind this is that employers are more willing to employ individuals of higher education as they are a better match with the job requirements (Blázquez \& Jansen 2008), or, in other words, high-skilled workers have a higher capacity to grasp the ever growing development of new and complex instruments used in the job (Goldin $\&$ Katz 2008). The described consequences of such technological progress can be attributed towards skilled obsolescence giving rise to skills mismatch.

As the world exits the third industrial revolution, known as the information age, and enters a new digitally connected post-information age, demand of skills have and will shift yet again as information technology continue to evolve, similarly resulting in skills mismatch. However, in addition to the low-skill and highskill divide in jobs that emerged from the previous two industrial revolutions, it is anticipated that the information age will result in a new critical divide between impersonally delivered services and personal services (Blinder 2006). Knowledge-replacing technology such as artificial intelligence, data-mining, and pattern recognition algorithms will convert more personal services into impersonal ones. These conditions indicate a current shift towards a knowledgebased economy (OECD 1996; Al-Zboon et al. 2014) where 'knowledge has become the key economic resource and the dominant, perhaps, even the only source of competitive advantage' (Drucker 1995: 271) for firms and the overall economy. Thus, human capital obsolescence is rapidly becoming a significant issue considering the increasing role of intellectual capital to obtain competitive advantage (Lenka 2012; Bhaskar, Bhal \& Ratnam 2003). 
Each of the industrial revolutions has resulted in a phenomenon labelled as technological unemployment. However, this will only remain a temporary phase of unemployment as long as society and the economy take appropriate measures to adjust to increasing productivity levels (The Economist 2014). Consequently, this creates growing pressure on individuals to constantly 'update' themselves and organisations to ensure that their human resource management (HRM) are adaptable to changing business needs in order to remain competitive (Chauhan \& Chauhan 2009). To fully understand the consequences of the role of technology in changing skill needs within the workforce and to determine what actions need to be taken to adjust to such changes, there is a need for an ongoing related discourse. In his 1996 article, Theodore Lewis began to explore and examine relevant theory, hypotheses and questions, and relevant conceptual frameworks on this discourse by 'focusing on issues, challenges, and approaches' (p. 45) that are crucial in studying the impact of technology on the workforce today. Building onto Lewis' work in 1996, this paper aims to re-examine this discourse under modern context 20 years later. Thus this paper will first explore the implications of skills mismatch as a result of skills obsolescence for the economy and labour market, and second, offer suggestions on the role of individuals, organisations, and talent brokers to overcome skills mismatch.

\section{Implications of skills obsolescence}

\section{Skills mismatch}

Technological progress has led to skill obsolescence: 'the degree to which professionals lack the up-to-date knowledge or skills necessary to maintain effective performance in their current or future work roles' (Kaufman 1974: 23), or the discrepancy between an individual's work performance and the required competency level (Chauhan \& Chauhan 2009) as a result of an upgrade of required worker skill level and/or a shift in types of skills required. Subsequently, this gives rise to heterogeneity within the labour market where workers are differentiated with respect to their skills and firms are differentiated by their job requirements (Thisse \& Zenou 2000). Manacorda and Petrongolo (1999) refer to the discrepancy between the demand and supply of skills composition in the labour market as 'skills mismatch'. Skills mismatch has the ability to pose as a risk to the labour market by contributing to rising unemployment level. However, depending on the market conditions, efficiency of job-matching allocation, and adopted model of skills obsolescence, this may not always be the case.

Firstly, according to the definition of skills mismatch and with respect to the market conditions, when the demand and supply of workers' skills move proportionately in the same direction, unemployment level will not be affected by skills mismatch. However, when demand and supply of skills do not move with 
the same proportion, skills mismatch will negatively affect unemployment rates (Manacorda \& Petrongolo 1999). In other words, when the demand of intellectual human capital or knowledge is greater than the supply, there will be growing disparity of wages, and subsequently unemployment levels, because firms have the tendency to provide greater compensation for individuals with higher education (Greenspan 1996; Manacorda \& Petrongolo 1999; Badillo-Amador \& Vila 2013).

Secondly, the way in which the labour market manages its resource allocation can also influence the impact of skills mismatch on unemployment. The impact of skills mismatch is greatest when high-skill workers accept all jobs of varying skill requirements, but lowest when they exclusively accept high-skill jobs'cross-skill matching' job allocation and 'ex-post segmentation' respectively (Blázquez \& Jansen 2008). This is under the condition that demands for highability workers are greater than the demand for low-ability workers.

Finally, the type of skill obsolescence model adopted by an organisation will influence the learning process undertaken by a worker that is necessary to keep their skills updated and reduce the risk of layoff. The type of model is determined by the organisation's operating structure. Allen and de Grip (2012) identify the existence of two models of skill obsolescence: the dynamic model and the static model. In the dynamic skill obsolescence model, skills mismatch pose little risk to the probability of a worker becoming unemployed because the firm is structured in such a way where jobs are complex with constantly changing job contents. Subsequently, an employee's learning process is seen as endogenous to the organisation in which sufficient opportunities for learning is provided as a result of the job's structural characteristic. In such dynamic work environments, there is a constant balance between shifts in the skills requirements of the job and the updating of skills; both employees and employers are motivated to regularly invest in training so that they may overcome each new 'wave' of obsolescence when technology and knowledge evolve yet again. The greater the time and financial investment placed on any individual, the greater the incentive for the firm to prolong the employment duration for that individual as the firm has an expectation to gain an equivalent or greater amount of return for their investment. In this model, skill obsolescence may be viewed as an indicator of a healthy and adaptive environment with high learning potentials. Conversely, the static model of human capital obsolescence views learning as an exogenous process to the organisation and assumes that an employee's skill level remains moderately stagnant throughout their career. Thus in this model, skills mismatch can pose as a significant contributor to unemployment because changes in technology readily changes the skill requirements of a given job.

While it is true that technological changes can cause both an improvement and a deterioration of skills mismatch, there is significantly a greater number of ways in which such changes lead to negative implications on employment and the workforce (Allen \& de Grip 2012). Assuming a disproportionate demand 
and supply of skill, a cross-matching allocation of jobs, and a static model of obsolescence, the following section will explore the implications of technologyinduced skill mismatch for both employees and employers.

\section{Job insecurity, job satisfaction, and productivity}

Skills mismatch can impact workers' wellbeing and career in a number of ways. Skills mismatch is known to generate unwanted effects on the distribution of income (Allen \& de Grip 2012; Chauhan \& Chauhan 2009; Badillo-Amador \& Vila 2013; Cedefop 2010; de Grip 2004; Greenspan 1996). According to research conducted by Badillo-Amador \& Vila (2013), employees who hold a higher education level than is required for the job (overeducated workers) tend to earn less than the optimum amount of wage had their skills been utilised effectively. On the other hand, undereducated workers usually earn higher income streams than is appropriate for their skill level. In an extreme situation where the skills gap is significantly large and there is little opportunity available to narrow the margin, skills mismatch has been known to contribute to rising unemployment levels; workers are often forced to move into worse jobs or lose their employment altogether (Allen \& de Grip 2012; Dunkerly 1996). Consequently, risks of unemployment means that skills mismatch impart a relatively high 'degree of insecurity, uncertainty, and fear to job-holders' (Allen \& de Grip 2012; Greenspan 1996). Workers who have little means to overcome skills obsolescence develop a fear of it, continuously doubting whether the skills they have obtained through secondary and tertiary education will ever be sufficient to match the frequent upgrades of skills demanded in a job requirement. It has also been observed that workers are becoming increasingly willing to forgo income hikes in return for job security (Vieira 2005), essentially increasing the risk of securing an adequate standard of living (Allen \& de Grip 2012). On a psychological level, employees who have the awareness but lack the ability to triumph over skills obsolescence often have growing feelings of incompetence, leading to low levels of self-esteem and self-confidence (Chauhan \& Chauhan 2009). In summary, skills mismatch is known to be correlated with low job satisfaction as a result of unequal wage distribution, underutilisation of skills, and fear of job insecurity.

The effects of skills mismatch on workers in turn have flow-on ramifications for the profitability of an organisation (Allen \& de Grip 2012; Cedefop 2010; Kochan 2012). Reduced job satisfaction as a result of over-education negatively impacts firm performance as workers are restricted from fully utilising the utmost potential of their skills and education. Reduced job satisfaction as a result of fear and low self-esteem has often led to an overall decrease in involvement in team activities as reflected through behaviours of avoidance and absenteeism (Chauhan \& Chauhan 2009). Furthermore, in instances where an organisation experiences a shortage of skills supply, firms are often forced to place low-skilled workers in job positions that normally require high-skilled workers, thus often allowing employees to 
take advantage of the situation by using their position as leverage to favourably change the terms and conditions of their contract. Both of these outcomes lead to inefficient productivity (Cedefop 2010). In addition, a skill-job mismatch is a general indication of inefficient resource allocation in the economy since workers' skills and knowledge are not optimally utilised for output production (BadilloAmador \& Vila 2013; Thisse \& Zenou 2000).

\section{Embracing skills mismatch}

As evolving information technology will continue to ease the deliverance of skills through a wire, the critical divide between low-skill and high-skill jobs as well as impersonal and personal services will simultaneously increase unless adjustments are made. Hence, it is in the best interest of both employees and employers to proactively develop strategies to embrace the inevitable shift towards an increasingly obsolete workforce.

\section{The role of talent brokers}

Widely referred to as job placement, the role of a talent broker has existed even before the post-information age. However, changes in technology and the rapid spread of globalisation has seen an evolution in its role, giving rise to the growing significance of talent brokers as a mechanism to facilitate the process of effectively matching up the supply and demand of skills in the workforce in order to avoid social repercussions and increase productivity. This is supported by the role that knowledge now plays in obtaining competitive advantage and the fact that skills mismatch reflects an inefficient allocation of human capital. Current workers who are facing obsolescence and future workers seeking job opportunities should not only favourably consider seeking assistance from talent brokers, but also consider filling in the gap created by growing needs for people who are able to assess and efficiently allocate the skills of workers to ensure high levels of productivity (Borghans \& de Grip 2000). Similarly, organisations can also benefit from talent brokers. Given that contingent workers currently make up 30-40 per cent of the workforce (Davis et al. 2015), firms have been recommended to establish relationships with talent broker organisations in order to tap into the pool of flexible talent so that transitions during shifts in demand of skills can be achieved with ease. In strategic HRM, talent brokers can play a crucial role in talent analysis and in the adoption of a 'total talent' approach; this will be further discussed in sections below.

\section{Job opportunities and individual initiatives}

A Committee for Economic Development of Australia report (CEDA 2015) estimated that 40 per cent of Australian jobs and 47 per cent of the workforce respectively have a high likelihood to disappear in the next 10 to 16 years due to computerisation, thus increasing an employee's fear of becoming obsolete 
in the labour market. This includes both low-paid, manual jobs and high-paid, white-collar occupations, such as butchers, accountants, lawyers, book keepers, postal clerks, dentists, and much more (The Economist 2014). Even in the United States job growth has dropped from 31.3 per cent in the 1960s to -1 per cent in the 2000s, illustrating how dismal job prospects have become (Rotman 2013). However, as much as there are work and job risks due to technology, there are also plenty of opportunities arising as a result of technologically induced changes and numerous initiatives that workers can take to overcome skills mismatch.

John F. Kennedy proclaimed in 1962 that if men have the talent to invent new machines that put men out of work, they have the talent to put those men back to work; the same is true today. While new technology is known to destroy jobs especially among the low-skilled, studies have indicated that technology development can also create job opportunities (Michelacci \& Lopez-Salido 2007; Mortensen \& Pissarides 1998; OECD 1998). This is particularly true for employment in two particular sectors. Firstly, for knowledge-intensive sectors such as medicine, where specialist knowledge is required to help navigate through the complex nature of such industries (OECD 1998; Stewart, De $\&$ Cole 2015). The contribution that technology has made towards the widening economical inequalities can be seen as a fragmentation within the various work sectors of the organisation, further spurring the growing need for specialists and entrepreneurships (Theobald 1994). As such, the emerging trend of increasing numbers of talent brokers facilitating talent exchanges is also a clear indication of this shift towards the role of specialists (The Economist 2013). Secondly, in the technology sector (Vainiomaki \& Laaksonen 1999) there is a growing need for jobs that help drive further technology development: in the past 35 years the UK alone has witnessed an increase in number of information technology managers and software development professionals by a factor of 6.5 and 3 respectively (Stewart, De \& Cole 2015). Similarly, a report conducted by du Rausas et al. (2011) found that for every job destroyed, the internet creates 2.4 additional jobs.

For individuals in jobs at risk of skills obsolescence, employees can undertake initiatives for lifelong learning and skills updating to bridge the skills mismatch gap. This entails current and future workers adopting both short-term and longterm objectives of continuous self-development. Workers should seek to stay up-to-date with current developments in their career field by actively building on their knowledge base through reading professional journals, researching on the workings and structure of comparable firms, and actively attending or participating in relevant conferences. Challenging oneself by becoming involved in the operation of related departments can also decrease the risk of obsolescence as it helps develop functional flexibility through the expansion of different experiences, as well as understanding of the current workplace beyond the boundaries of the job requirements (Chauhan \& Chauhan 2009; van Loo, de Grip \& de Steur 2001). In 
short, the shift towards a knowledge-based service industry as a result of technology redefines the educational needs for employees, encouraging the approach towards lifelong learning (Beck 2010; de Grip 2004).

\section{Organisational level: Strategic human resource management}

Given that technology advancements will continue to change business needs and skills requirements, the traditional models for HRM, which simply emphasise managing rather than investing in employees, will no longer be sufficient to build a high-performing and sustainable workforce. The need to shift towards more strategic HRM has become increasingly recognised (Davis et al. 2015; Kalleberg 2012; Kochan 2012; The Economist 2014; Varon 2013; Willyerd 2013). Strategic HRM is 'an approach to managing human resources that supports long-term business goals and outcomes with a strategic framework' that 'focuses on longerterm people issues, matching resources to future needs, and macro-concerns about structure, quality, culture, values and commitment'(CIPD 2015: para 1). In essence, strategic HRM reflects a manager's understanding of the mismatch between the skills that a firm currently has and the skills that will be needed in the future, and the ability to plan ahead and execute actions in order to eliminate that mismatch. It is a tactic that requires managers to adopt the perspective of a business analyst in order to understand and foresee macroeconomic trends so that they are able to identify corresponding shifts of skills demand in the labour market. Key features of a strategic HRM include talent analytics, a 'total talent' approach, and healthy work environments.

Talent analytics is the process of mining talent data through processes such as talent mapping, models, and HR software in order to review the performance and potential of current employees or to work backwards by identifying critical future jobs and skills that will be required. This process can be conducted internally within the firm or via an intermediary, for example, a talent broker. Talent analytics is a crucial part of strategic HRM as it provides important information on employee skill gaps, anomalies indicating possible job migration of an employee, and areas of strengths and areas for development (Davis et al. 2015). Such information is necessary to help managers make decisions regarding hiring, compensation plans, and restructuring of the firm in order to manage the balance between a firm's current and future talent supply (Varon 2013). However, the significance of investing in talent data and its ability to deliver tangible returns to the firm has yet to be widely recognised and, as a result, talent analytics is still being undervalued and underused. Another reason why talent analytics is rarely utilised is due to the skills gap experienced by HR managers. Data collected through the Global Human Capital Trends survey conducted by Deloitte in 2014 revealed that 86 per cent of firms admitted the lack of HR analytic capabilities and that 67 per cent of HR managers consider themselves to be 'weak' at handling talent data (Davis et al. 2015). 
A 'total talent' approach to the workforce is an embracing of the talent ecosystem. One of the most significant changes in the service economy as a result of technological advancement is the expansion of the workforce definition. With information technology continually contributing to the knowledge-based economy, new ways to complete jobs remotely and independently are constantly appearing. As a result, workers are becoming less loyal and are increasingly turning to entrepreneurship or talent brokers in order to export their talents (Varon, 2013). This is further exacerbated by the fact that since the twentieth century, the perceived significance of skills development as a tool to build and maintain employee loyalty has slowly diminished. This is indicated through the significant decrease in technical training received by workers throughout the years, where an average of two and a half weeks of training per year were received by most if not all employees in 1979 compared to zero training in five years for almost 80 per cent of employees in 2011 (Willyerd 2013). Consequently, there is a growing recognition of the 'open talent economy' that balances the 'investments in employee development with hiring from outside the company to fill unanticipated gaps' (Willyerd 2013: 5). In addition to establishing relationships with talent brokers, another suggestion for $\mathrm{HR}$ managers is to establish alumni networks in order to enforce good relationships with contingency workers.

Finally, establishing healthy work environments that provide good working conditions (Davis et. al 2015; Zerzan 2009), flexible work arrangements and compensation systems (Murphy 2002), and lifelong learning opportunities (Allen \& de Grip 2012; Kalleberg 2012) with a solid training and benefits program (Davis et al. 2015) will strengthen an employee's loyalty contract and will attract other talented and ambitious job seekers. Additionally, this will help eliminate concerns of losing the firm's investment in human capital.

While strategic HRM is a widely recognised approach for resolving the challenges of technology's impact on work and jobs, it should be recognised that variances between different firms and industries in terms of size, capacity, and resource availabilities are relevant factors in determining the success or failure of the adoption of strategic HRM. According to an analysis conducted by the Organisation for Economic Co-operation and Development (OECD 2011), there are significantly greater challenges for small-to-medium enterprises (SMEs) in successfully applying strategic HRM. This is caused by difficulties in accessing educational and skills development programs due to limited time and resources, lack of managerial skills, lack of enterprise experience and support, lack of awareness, differences in learning and training preferences and needs, and complicated paperwork (OECD 2011). Consequently, there is a noticeable bias towards large firms in the provision of skills development, where participation in such programs is 50 per cent greater in large firms compared to SMEs (Kubitz 2011). 


\section{Conclusion}

With the third industrial revolution still underway, there is a risk that technological unemployment will become a permanent issue unless society and the economy adjust to minimise skills mismatch. To bridge the skills gap between highly educated and less-educated people, pursuit of lifelong learning, whether individually sought or facilitated by organisational institutions, appears to be the most effective solution. However, in slowing the skills mismatch between personal and impersonal services, employers and employees have different roles to play. At an individual level, adapting to meet the growing demand for specialists and entrepreneurs is the recommended course of action in order to prevent becoming obsolete. On an organisational level, firms should shift towards a strategic HRM approach in order to remain flexible and adaptable to changing business needs and skills demand. Firms that have already adopted strategic HRM understand that proper investment in human capital will help minimise the rate of skills mismatch and thus lead to an increase in productivity. Furthermore, it is found that talent brokers have a growing role as an effective mechanism in facilitating businesses and individuals to meet their supply and demand needs of skills and prevent social consequences of inefficient use of human capital.

This paper highlighted the implications of an expanding knowledge base, both in the form as information and as technology, on society and its functions. As humanity continues its pursuit towards greater knowledge, it is uncertain what future industrial revolutions would look like and how they will impact society. Regardless, despite the fact that technology has high potential in hindering job creation, history has suggested that as workers adjust their skills and businesses continue to seek and create opportunities based on advancing technology, job availability will rebound. However, the question is, will today's and future digital technologies be different? Or will they break the observed trend and instead create long-term involuntary unemployment? Finally, as this article is simply intended to act as a catalyst for future investigation, it should be acknowledged that there is still much room to explore this discourse. Factors such as firm scope, gender, geographical, and political implications are all important aspects to explore if we are to gain a comprehensive global understanding on the impact of technology on the workforce. 


\section{Bibliography}

Allen, J., and de Grip, A., 2012, 'Does skill obsolescence increase the risk of employment loss?', Applied Economics, vol. 44, no. 25, pp. 3237-3245.

Al-Zboon, M.S., Al Mwadiah, R., Al Jaafreh, A., Al-Rabdi, I., and Mohammad, M., 2014, 'Future justification for the shift towards the knowledge based economy in Jordan from educational experts' viewpoint', Journal of Economics and Sustainable Development, vol. 5, no. 6, pp. 160-171.

Badillo-Amador, L., and Vila, L.E., 2013, 'Education and skill mismatches: wage and job satisfaction consequences', International journal of Manpower, vol. 34, no. 5, pp. 416-428.

Beck, J., 2010, 'Independent workforce theory: implications for HRD', Human Resource Development International, vol.6, no. 1, pp. 21-41.

Bhaskar, A.U., Bhal, K., and Ratnam, C.S.V, 2003, 'Ethical issues in change management: an empirical study', Journal of Human Values, vol. 9, no. 1, pp. 19-27.

Blázquez, M., and Jansen, M., 2008, 'Search, mismatch and unemployment', European Economic Review, vol. 52, no. 3, pp. 498-526.

Blinder, A.S., 2006, Offshoring: the next industrial revolution?, Foreign Affairs, www.foreignaffairs.com/articles/2006-03-01/offshoring-next-industrialrevolution, accessed 13 April 2015.

Borghans, L., and de Grip, A., 2000, The debate in economics about skill utilization, in The overeducated worker: the economics of skill utilization, Edward Elgar Publishing, United Kingdom, pp. 3-26.

CEDA, 2015, Australia's Future Workforce?, Committee for Economic Development of Australia, www.ceda.com.au/research-and-policy/policypriorities/workforce, accessed 9 April 2015.

Cedefop, 2010, The skill matching challenge: Analysing skill mismatch and policy implications, European Cenre for the Development of Vocational Training, Publications Office of the European Union, Luxembourg.

Chauhan, S.P., and Chauhan, D., 2009, 'Are you on the verge of obsolescence?', Indian Journal of Industrial Relations, vol. 44, no. 4, pp. 616, 659.

CIPD, 2015, Strategic buman resource management, Chartered Institute of Personnel and Development, www.cipd.co.uk/hr-resources/factsheets/ strategic-human-resource-management.aspx, accessed 1 April 2015. 
Davis, H., Martindale, M., Matthews, D., Orton-Jones, C., Smith, E., and Tokc-Wilde, I., 2015, ‘Talent management 2015’, Raconteur, no. 301, pp. 2-15.

de Grip, A., 2004, Evaluating human capital obsolescence, paper presented to the joint EC-OECD Seminar on Human Capital and Labour Market Performance, Brussels, www.oecd.org/els/emp/34932083.pdf, accessed 1 April 2015.

Drucker, P.F., 1995, Managing in a time of great change, ButterworthHeinemann, Oxford.

du Rausas, M.P., Manyika, J., Hazan, E., Bughin, J., Chui, M., and Said, R., 2011, Internet matters: The net's sweeping impact on growth, jobs, and prosperity, McKinsey \& Company, www.mckinsey.com/industries/high-tech/ourinsights/internet-matters, accessed 4 April 2015.

Dunkerley, M., 1996, The jobless economy?, Blackwell Publishers Limited, Cambridge, United States of America.

Goldin, C., and Katz, L.F., 2008, The race between education and technology, Harvard University Press, United States of America.

Greenspan, A, 1996, 'Technology change and job insecurity', Compensation and Benefits Management, vol. 12, no. 4, pp. 1-6.

Kalleberg, A.L., 2012, 'The social contract in an era of precarious work', Pathways Fall, pp. 3-6.

Kaufman, H.G., 1974, Obsolescence and professional career development, Amacom, New York.

Kochan, T., 2012, A jobs compact for America's future, Harvard Business Review, hbr.org/2012/03/a-jobs-compact-for-americas-future, accessed 13 April 2015.

Kubtiz, M., 2011, Leveraging training skills development in SMEs: an analysis of Zaglebie sub-region, Poland, in OECD Local Economic and Employment Development (LEED) working papers, OECD Publishing, www.oecd.org/ cfe/leed/47081344.pdf, accessed 13 April 2015.

Lenka, K., 2012, 'Employers' view on problems related to workforce skills and qualification', Journal of Competitiveness, vol. 4, no. 4, pp. 50-66.

Lewis, T., 1996, 'Studying the impact of technology on work and jobs', Journal of Industrial Teacher Education, vol. 33, no. 3, pp. 44-65.

Manacorda, M., and Petrongolo, B., 1999, 'Skill mismatch and unemployment in OECD countries', Economica, vol. 66, no. 262, pp. 181-207. 
Michelacci, C., and Lopez-Salido, D., 2007, 'Technology shocks and job flows', Review of Economic Studies, vol. 74, pp. 1195-1227.

Mortensen, D.T., and Pissarides, C.A., 1998, 'Technological progress, job creation, and job destruction', Review of Economic Dynamics, vol. 1, pp.733-753.

Murphy, M., 2002, Organizational change and firm performance, in OECD Science, Technology and Industry Working Papers, OECD Publishing, dx.doi. org/10.1787/615168153531, accessed 12 April 2015.

OECD, 1996, The knowledge-based economy, Organisation for Economic Co-operation and Development, Paris.

OECD, 1998, Technology productivity and job creation: best policy strategies, OECD Publishing, www.oecd.org/sti/ind/2759012.pdf, accessed 4 April 2015.

OECD, 2011, Towards an OECD skills strategy, OECD Publishing, www.oecd. org/edu/47769000.pdf, accessed 15 April 2015.

Puricelli, F.T., 2011, 'Early twentieth century transportation technology and the creation of modern American culture', MA Thesis, Graduate School of the College of Charleston and the Citadel, South Carolina.

Rotman, D., 2013, How technology is destroying jobs, MIT Technology Review, accessed 13th April 2015, www.technologyreview.com/featuredstory/515926/ how-technology-is-destroying-jobs/.

Stewart, I., De, D., and Cole, A., 2015, Technology and people: the great job-creating machine, Deloitte, accessed 15th April 2015, www2.deloitte.com/content/dam/ Deloitte/uk/Documents/finance/deloitte-uk-technology-and-people.pdf.

The Economist, 2012, 'The third industrial revolution', The Economist, www. economist.com/node/21553017, accessed 27 April 2015.

The Economist, 2013, 'The workforce in the cloud', The Economist, www.economist. $\mathrm{com} /$ news/business/21578658-talent-exchanges-web-are-starting-transformworld-work-workforce, accessed 13 April 2015.

The Economist, 2014, 'The onrushing wave', The Economist, www.economist.com/ news/briefing/21594264-previous-technological-innovation-has-alwaysdelivered-more-long-run-employment-not-less, accessed 15 April 2015.

Theobald, R., 1994, Understanding industrial society, The Macmillan Press Limited, Great Britain, pp. 87-125.

Thisse, J.-F., and Zenou, Y., 2000, 'Skill mismatch and unemployment', Economics Letters, Vol. 69, pp. 415-420. 
Vainiomaki, J., and Laaksonen, S., 1999, 'Technology, job creation and job destruction in Finnish manufacturing', Applied Economic Letters, vol. 6, no. 2, pp. 82-88.

van Loo, J., de Grip, A., and de Steur, M., 2001, 'Skills obsolescence: Causes and cures', International Journal of Manpower, vol. 22, no. 1/2.

Varon, E., 2013, 'How to build a more sustainable relationships between companies and employees', SAP Center for Business Insight, no. 32 .

Vieira, J.A.C., 2005, 'Skill mismatches and job satisfaction', Economic Letters, vol. 89, pp. 39-47.

Willyerd, K., 2013, 'A new vision for HR management: The workforce ecosystem', SAP Center for Business Insight, no. 33.

Zerzan, J., 2009, The mass psychology of misery, The Anarchist Library, theanarchistlibrary.org/library/john-zerzan-the-mass-psychology-of-misery, accessed 1 April 2015. 
This text is taken from The ANU Undergraduate Research Journal, Volume Seven, 2015, edited by Daniel McKay, published 2016 by ANU eView, The Australian National University, Canberra, Australia. 